\title{
GEWALT e uma Crítica Socioambiental
}

\section{GEWALT and a Socioenvironmental Criticism}

\section{Resumo}

Vera Marta Reolon ${ }^{1}$

Partindo da conceituação das três ecologias propostas por Felix Guattari, como podemos e (se) devemos intervir para tornar ambientes, sujeitos e instituições mais aptos a viver no mundo contemporâneo, propiciando melhor bem-estar aos ambientes e aos membros da população. Só uma articulação ético-política ECOSOFIA - entre os três registros ecológicos: do meio ambiente, das relações sociais e da subjetividade podem esclarecer as questões. Necessários novos dispositivos de produção de subjetividades individuais e coletivas. Égide ético-estética de uma ECOSOFIA. Gewalt. A violência e suas diferentes esferas de atuação. O poder, aquele aliado da liderança, e o poder que aliena e escraviza, vinculado à paranoia. Humano, que é humano? Desejo. Ação. Liberdade. Responsabilidade. Os estilos de vida, sua escolha no viver. A ação humana. O trabalho.

Palavras-chave: Contemporaneidade, Crise Ecológica, Possíveis Soluções, Poder, Ação, Humano

\section{Abstract}

Starting from the conceptualization of the three ecologies proposed by Felix Guattari, how can and (if) we intervene to make environments, subjects and institutions more apt to live in the contemporary world, providing better well-being

\footnotetext{
${ }_{1}$ Psicanalista, psicóloga (CRP 07/7654), jornalista (Mtb 16.069), curadora e crítica de arte, professora (FACED/UFRGS). Doutora em Filosofia (PUC-RS), Doutora em Educação (UFRGS), Mestre em Letras e Cultura Regional (UCS), Graduada em Psicologia - Formação de Psicólogo (UCS), Bacharel em Ciências Contábeis (UCS). Coeditora do site apolineo.net. Autora de "mulheres para um homem... para O Homem, A Mulher" (Edipucrs, 2008).

E-mail: verareolon@terra.com.br
} 
to environments and members of the population. Only an ethical-political articulation - ECOSOPHY - between the three ecological records: the environment, social relations and subjectivity can clarify the issues. New devices for the production of individual and collective subjectivities are needed. Ethical-aesthetic aegis of an ECOSOPHY. Gewalt. Violence and its different spheres of action. Power, that ally of leadership, and the power that alienates and enslaves, linked to paranoia. Human, who is human? Desire. Action. Freedom. Responsibility. Lifestyles, your choice to live. Human action. The work.

Keywords: Contemporaneity, Ecological Crisis, Possible Solutions, Power, Action, Human.

O que é ECOLOGIA? Sempre que falamos em Ecologia nos remetemos diretamente a questões ambientais, ao meio ambiente, ao mundo que nos cerca, à natureza!

Mas, o que é ECOLOGIA mesmo?

ECO: da raiz grega öikos: lar, bem doméstico, habitat, meio natural.

Então, o que pensamos ao sinalizar o termo Ecologia torna-se muito mais amplo, pois nos remete à casa, ao lar, ao habitat. Vamos, assim, muito além do estudo do meio ambiente, da natureza. Estudamos o ambiente doméstico, social, coletivo, o eu pessoal, a natureza que nos abarca, enfim todo o ambiente que habitamos, inclusive nosso próprio corpo.

\section{As Três Ecologias de Guattari}

Guattari irá partir de uma Análise Institucional. Para ele, há uma progressiva deterioração nos modos de vida humanos, individuais e coletivos. A esses fenômenos, denominará de “desequilíbrio ecológico". Nomeará tais fenômenos de infantilização regressiva. Dirá que só uma articulação ético-política, que nomeia ECOSOFIA, entre os três registros ecológicos - do meio ambiente, das relações sociais e da subjetividade - podem esclarecer as questões.

\subsection{Capitalismo Mundial Integrado}

Necessária é uma revolução social, política e cultural, com o fim de 
reorientar objetivos de produção de bens materiais e imateriais. Essa revolução deverá ser das forças visíveis, mas também de domínios moleculares de sensibilidade, inteligência e desejo.

Modos dominantes de valorização das atividades humanas concentrados em estabelecer, no mesmo patamar, bens materiais, culturais, áreas naturais: o patamar do mercado, além de colocar o conjunto das relações sociais e internacionais sob a direção das máquinas policiais e militares.

Há um sistema de capitalismo mundial integrado, que estimula a miséria, a fome, a morte, grandes centros de exploração e, ainda, o reforço: há uma exacerbação das questões de imigração e racismo.

Os jovens ficam concentrados numa esfera cultural de pseudo-identidade rock, isolados em um mundo de alienação, de distanciamento social, vivendo em "tribos".

Tudo isso leva a uma fratura social extrema.

\subsection{Revolução Ecosofia}

Ecosofia propõe uma reconexão das práxis humanas nos mais variados domínios. Necessários novos dispositivos de produção de subjetividades individuais e coletivas. No lugar de uma usinagem pela mídia, que só conduz ao desespero:

- Formação de líderes carismáticos

- Criação artística liberta do mercado

- Ecosofia mental libertada de fantasmas e máscaras

Se não houver uma rearticulação dos três registros da ecologia (mental, social e ambiental), podemos pressagiar a escalada de:

- Racismo

- Fanatismo religioso

- Cismas nacionalitários (com fechamentos reacionários)

- Exploração do trabalho infantil

- Opressão feminina

Ao invés de sujeitos, teríamos componentes de subjetivação trabalhando cada um por conta própria (conjuntos sócio-econômicos, máquinas 
4 | Dossiê - Natureza e Sociedade no Antropoceno - Superando a Separação?

informacionais, etc.) - o sujeito seria apenas um "Terminal". Tudo se passa como se um "sistema científico" exigisse do sujeito coordenadas de vivências fora dele. Necessário livrar-se dos paradigmas científicos em favor de novos paradigmas ético-estéticos.

Dois pontos devem ser levados em consideração:

1. A apreensão do fato psíquico como inseparável do agenciamento de enunciação, como fato e processo expressivo. Fato e processo não desvinculados, mas em relação

2. Deve haver uma inteligibilidade discursiva - tarefa específica do cuidador (também do professor, em sala de aula), que difere de todo trabalho de mídia tecnológica.

Expressar-se para chegar ao outro (em relação) e discutir com o outro os fatos da vida, com o intuito de elucidá-los.

\subsection{Insustentabilidade Ética}

Devemos fazer do fato freudiano outro uso, desmascarar a psicanálise sem fantasmas e mitos, torná-la extensiva, realizar intervenções não apenas no campo psi, mas na educação, na saúde, na cultura, no esporte, na arte, na mídia, na moda. Deve-se sair da insustentabilidade ética abrigada na neutralidade, sustentada em um corpus científico e buscar interfaces com campos estéticos.

Fim dos catecismos psicanalíticos, comportamentalistas e sistemistas. $\mathrm{O}$ povo psi convergindo com o mundo da arte se desfaz de aventais brancos, de linguagem opressiva e da forma de ser para fazer evoluir sua prática tanto quanto suas bases teóricas. Recomposição das práticas sociais e individuais através de três rubricas complementares:

ecologia social,

ecologia mental e

ecologia ambiental.

Égide ético-estética de uma ECOSOFIA para fugir dos quatro regimes semióticos que compõem o Capitalismo Mundial Integrado: a semiótica econômica, a semiótica jurídica, a semiótica técnico-cientifica e a semiótica de subjetivação. 


\subsection{Passividade e homeless}

Um dos problemas dessa modernidade tardia é a questão do sujeito manterse passivo diante do imposto pelas mídias e pelas políticas. Precisamos aprender a pensar transversalmente as diferentes interações entre cultura e natureza para evitar o efeito do que Guattari chama de homeless (instalação de conglomerados e arranha-céus, arrastando a população para a marginalidade e a periferia). Não desaparecem apenas as espécies, mas também as palavras, as frases, os gestos de solidariedade humana.

\subsection{Ecologia Social}

Deverá trabalhar na reconstrução das relações humanas em todos os níveis do socius. Tornou-se igualmente imperativo encarar seus efeitos no campo da ecologia mental, no seio da vida cotidiana individual, doméstica, conjugal, de vizinhança, de criação e de ética pessoal. A subjetividade capitalística se esforça por gerar o mundo da infância, da ordem da loucura, da dor, da morte, do sentimento de despertencimento - se anestesia num sentimento coletivo de pseudo-eternidade. São necessárias novas práticas micro-políticas e micro-sociais; que as práticas sociais e políticas trabalhem para a humanidade e não mais para um simples reequilíbrio permanente do universo em semióticas capitalísticas.

\subsection{Ecologia Ambiental}

Cada vez mais os equilíbrios naturais dependerão das intervenções humanas. Interessante seria pensarmos em requalificar a ecologia ambiental como uma ecologia maquínica, porque sempre será uma questão das máquinas e, especialmente, das máquinas de guerra. Sempre pensando numa ética ecosófica: em políticas focalizadas no destino da humanidade.

\subsection{Ecologia Mental}

Julgada em função de: 
1. Capacidade de circunscrever cadeias discursivas em ruptura de sentido

2. Possibilidade de operar conceitos, autorizando uma autoconstrutibilidade teórica e prática.

\title{
- Confusão público-privado
}

- Proteção à violência levando a mais violência (a questão da vigilância constante, os armamentos, a tecnologia que ocasiona o desemprego e sucessiva marginalização).

Necessária a promoção de práticas inovadoras, disseminação de experiências alternativas, centradas no respeito à singularidade e no trabalho permanente de produção de subjetividade, que vai adquirindo autonomia e, ao mesmo tempo, se articulando ao resto da sociedade.

\begin{abstract}
O principio comum às três ecologias consiste, pois, em que os territórios existenciais com os quais elas nos põem em confronto não se dão como um em si, fechado sobre si mesmo, mas como um para si precário, finito, finitizado, singular, singularizado, capaz de bifurcar em reiterações estratificadas e mortíferas ou em abertura processual a partir de práxis que permitam torná-lo 'habitável' por um projeto humano.
\end{abstract}

Não se trata de criar regras universais, como guias das práticas, mas de liberar as antinomias de princípio entre os três níveis ecosóficos. Agir, em Políticas Públicas, demanda conhecimentos que não se restringem a mera ação especulativa.

Necessitamos conhecer o campo cultural, as demandas sociais, o agir comunitário, as formas de aglomeração social, os ajuntamentos, as problemáticas advindas desses ajuntamentos e, mais do que tudo, necessitamos conhecer como as problemáticas acontecem. Logo, para resolver, ou, ao menos, buscar formas de amenizar problemas sociais decorrentes, cada vez mais, da violência, precisamos urgentemente, determinar, buscar conceituar o que é violência, nos diversos contextos culturais.

\section{Gewalt: Violência como Poder}

A violência acontece nos nichos culturais atentos às dependências químicas, cada vez mais presentes em nosso cotidiano social, mas também às dependências sociais.

Se pensarmos em um mundo estabelecido na e da dependência, aos moldes das manifestações apresentadas em todas as dependências químicas, urge que busquemos problematizar violência, mas, principalmente que determinemos modos de atuação social para reduzi-la, amenizá-la, eliminá-la do cotidiano, para que a vida em sociedade possa se 
dar. Se não providenciarmos soluções, tendemos a eliminar o social, tendemos ao desgoverno, a morte social.

São diversas as formas de violência existentes, a física, a moral, a social, a institucional, a marital, a familiar, a filial, a paternal... Mas existe uma violência que nos chega através das máximas formas de PODER, poder atento ao que Jacques Lacan, relendo Freud, entre outros, nomeia no campo das PSICOSES (aqui, especialmente no campo da PARANÓIA) E PERVERSÕES.

Necessário então conceituar estas estruturas psíquicas, levá-las aos meios sociais, pensar em produções sociais psicótico-perversas e conceituar violência, suas formas, os "establishment" do que vemos apresentar-se nos diferentes contextos sociais e na vida - ou poderíamos dizer morte em sociedade.

Então, a partir da obra de Sigmund Freud, de Jacques-Marie Lacan pensamos as estruturas clínicas. Através da obra de Walter Benjamin - Para uma Crítica da Violência buscamos a conceituação de Gewalt, pois Gewalt significa não só violência, como também poder legítimo, autoridade, força pública..., designa tanto a violência como o poder legítimo. Benjamin, segundo Jacques Derrida, em Força de Lei, conceitua Gewalt, e faz uma "Crítica à Violência".

Pensar, então, violência, a partir de movimentos de ataques e horror praticados uns contra os outros, distingui-la de "poder legítimo", se é que podemos fazê-lo, nos tempos atuais e pensar em formas de ação para isso, e/ou a partir disso, penso ser imprescindível para agir publicamente, principalmente no campo das políticas públicas, no agir político, na vida em sociedade, nos movimentos sociais, na educação, ..., na VIDA!

Como fazê-lo sem saber por onde andamos?

O que é VIOLÊNCIA - como conceituá-la, em que parâmetros e sob quê critérios; como ela se dá no social estabelecido no século XXI, há critérios ético-estéticos para determiná-la? Que políticas públicas podem ser implementadas, se é que já poderemos determiná-las, para agir de forma a, se não eliminá-la, reduzi-la?

\section{O Humano: desejo, estilo de vida, ação}

O que nos diferencia como humanos? O homem, em alguns momentos, dizse humano porque possui racionalidade, porque possui espírito, enfim diferentes conceitos, construções teóricas que, na verdade, nada dizem, são apenas palavras que não trazem respostas às nossas inquietações.

A psicanálise, como teoria interpretativa da realidade, serve para analisar os fenômenos, no campo individual, através das manifestações do inconsciente, 


\section{8 | Dossiê - Natureza e Sociedade no Antropoceno - Superando a Separação?}

presentes na linguagem dos diversos sujeitos, nos chistes, na interpretação dos sonhos, etc. Pode, entretanto, interpretar os fenômenos sociais, através da análise das manifestações da sociedade, das organizações e instituições, dos grupos sociais. Aliando-se a filosofia, essencial para seu desenvolvimento desde o início, a psicanálise, além de realizar interpretações, reflete sobre os fatos, utilizando-se das teorias dos grandes pensadores.

Partindo-se, assim, da escrita desconstrutiva de Derrida, o discurso psicanalítico é o que pode dar conta das questões contemporâneas: "Se há um discurso que poderia, hoje em dia, reivindicar a causa da crueldade psíquica como assunto próprio, este é o que se chama, de mais ou menos um século para cá, psicanálise" (DERRIDA, 2001, p.8-9).

Basta que eduquemos, que adestremos os animais, mesmo que selvagens, para observarmos neles amorosidade, carinho, dedicação. Se os tratarmos com amor, recebemos amor e dedicação para sempre. O ser humano também precisa desta "amarragem" amorosa, sem esta estruturação, sem esta dedicação ele fica perdido, como um objeto do Outro, este que o gerou. É preciso que o ser humano, ao nascer, ou antes disso, seja desejado, seja marcado com a insígnia do desejo por alguém, que ele tenha sido esperado, querido por alguém, mas não desejado para completar este alguém, e sim que ele seja desejado para viver, ser feliz, progredir, fazer-se. É um processo, e um projeto de humanização constante, que se inicia com este Outro.

Para que sejamos marcados como desejantes, tenhamos "voz plena de valor", precisamos da marca primordial de instituição narcísica, que denominamos Amor do Outro. Outro este que faz para nós um papel materno, de mãe instituidora da marca amorosa que levaremos em nossas vidas. Sem esta marca inicial não somos considerados estruturalmente sujeitos, donos de uma identidade, estaremos sempre presos a alguém que nos deve conduzir pela vida, pois esta marca é primordial, necessária em nossa frenética luta pela libertação. Com a marca podemos nos libertar e seguir. Sem a marca estamos presos ao desejo do Outro, às suas imposições.

O que nos torna humanos então, para a psicanálise, não nos deixando objetivar, ou sermos objetivados, é este amor de estrutura, que nos diferencia 
perante os demais, que nos torna desejantes, desejantes de vida, de felicidade, de busca.

Sartre vai além deste conceito, ele fala do existir humano, do processo da existência humana, como uma construção, construção essa que parte da própria liberdade de ser humano. O homem vai construindo sua existência, a partir da liberdade que possui, liberdade de escolher, conforme seu desejo: "toda verdade e toda ação implicam um meio e uma subjetividade humana" (SARTRE, 1970, p.01).

No texto sartriano, há uma noção de humanidade que extrapola toda a individualidade, todo egoísmo ou todo egocentrismo narcisista que o homem possa carregar, pois ele expõe a liberdade existencial humana como uma responsabilidade que inclui a humanidade inteira: "a nossa responsabilidade é muito maior do que poderíamos supor, pois ela engaja a humanidade inteira" (SARTRE, 1970, p.03).

Logo, em Sartre, toda nossa ação é livre, a partir de nossas escolhas, toda nossa ação é uma construção livre de nossa individualidade, uma marca individual de nossa existência, mas ela também é uma responsabilidade sobre a marca que transmitimos como retrato da humanidade toda e "sobre" toda essa humanidade. Essa responsabilidade carrega muita angústia, e daí a afirmação de Sartre de que o "homem é angústia" (SARTRE, 1970, p.04). Não há disfarces para a angústia, pois ela faz parte deste existir humano, de escolhas e de responsabilidade.

Kierkegaard vai propor que o homem deve/pode escolher/eleger como vai conduzir sua vida. Propõe dois estilos de vida, de escolha: o estilo de vida estético e o estilo de vida ético. Se o homem opta por seguir um estilo de vida estético (que aqui nada tem de estética - arte ou o que hoje entendemos pelo termo estética), ele é o que vive o INSTANTE (fronteira entre o antes e o depois). Em princípio ele viveria em liberdade. Mas na crítica que Kierkegaard faz a este "escolhedor", dirá que esta liberdade é um engodo, já que a verdadeira liberdade só se dá na opção pelo estilo de vida ético

o que vale é madurar a própria personalidade antes de formar o espírito. [..] desejarias fortalecer tua alma [..] tem em cada ser uma potência capaz de desafiar o mundo inteiro. [..] o principal da vida, reconquistar-te a ti mesmo, adquirir-te a ti mesmo, com a condição de que possas, o mais bem que queiras poder a energia necessária para fazê-lo. (KIERKEGAARD, 1966, p.9-11).

O estilo de vida ético, à semelhança do que ocorria no mundo grego, incorpora, abarca o que entendemos por estético. Ao optarmos pelo estilo de vida 
ético, incluímos em nossa opção a vida estética, incluímos a opção por nós mesmos, o eterno. O sujeito que opta pelo estilo de vida estético vive no desespero e nada tem de fato.

Tua escolha é uma escolha estética, mas uma escolha estética não é uma escolha. Em verdade, o fato de escolher é uma expressão real e rigorosa da ética [...] o único aut-aut (ou isto, ou aquilo) absoluto que existe é a escolha entre o bem e o mal e essa escolha também é absolutamente ética. (KIERKEGAARD, 1966, p. 20).

O desespero não deve ser um inibidor de minha ação. Ao contrário, deve me engajar na ação: "não é preciso ter esperança para empreender [...] não deverei ter ilusões e que farei o melhor que puder" (SARTRE, 1970, p.o8).

A realidade só existe a partir da ação, o homem só existe à medida que se realiza na ação, o homem é o conjunto de seus atos. Para Hannah Arendt, o homem não é um ser de natureza, é um ser de condição. A condição humana é que o homem é um ser de ação (arte) e discurso (político). Hannah diferencia labor de trabalho, mas dirá que a condição humana por excelência é o trabalho, ação humana que nos diz quem e o quê somos.

\begin{abstract}
Com a expressão vita activa pretendo designar três atividades humanas fundamentais: labor, trabalho e ação. [...] o labor é a atividade que corresponde ao processo biológico do corpo humano [...] tem a ver com as necessidades vitais [...] a condição humana do labor é a própria vida. $\mathrm{O}$ trabalho é a atividade correspondente ao artificialismo da existência humana. [...] a condição humana do trabalho é a mundanidade. A ação, única atividade que se exerce diretamente entre os homens sem a mediação das coisas ou da matéria, corresponde à condição humana da pluralidade. (ARENDT, 2008, p.15).
\end{abstract}

Independentemente se tomamos cada uma das atividades humanas ou se nos dedicarmos, abarcarmos o termo proposto por Hannah, vita activa, as três atividades referem-se ao que designa, distingue o homem como homem, à durabilidade do mundo, já que o homem o habita.

o trabalho de nossas mãos, em contraposição ao labor de nosso corpo - o homo faber que "faz" e literalmente "trabalha sobre" os materiais, em oposição ao animal laborans que labora e "se mistura com eles" - fabrica a infinita variedade de coisas cuja soma total constitui o artifício humano. (ARENDT, 2008, p.149).

Outros autores também nos apresentam a importância do trabalho na vida humana, para o seguir de sua existência: "No trabalho, o homem satisfaz uma potência de criação que se multiplica por numerosas metáforas" (BACHELARD, 2001, p.24). A própria Hannah vai nos conduzir, em seu texto A Condição Humana, 
o que faremos (ela já se questionava nos anos 60 do século $\mathrm{XX}$ ), sem trabalho: “O que se nos depara, portanto, é a possibilidade de uma sociedade de trabalhadores sem trabalho, isto é, sem a única atividade que lhes resta" (ARENDT, 2008, p.13).

E ela mesma nos aponta o que pode nos ter conduzido a esta "situação":

[..] talvez o desejo de fugir à condição humana esteja presente na esperança de prolongar a duração da vida para além do limite de cem anos. [..] O problema tem a ver com o fato de que as "verdades" da moderna visão científica do mundo, embora possam ser demonstrados em fórmulas matemáticas e comprovadas pela tecnologia, já não se prestam à expressão normal da fala e do raciocínio. [..]Se realmente for comprovado esse divórcio definitivo entre o conhecimento e o pensamento, então passaremos, sem dúvida, à condição de escravos indefesos, não tanto de nossas máquinas quanto de nosso know-how, criaturas desprovidas de raciocínio, à mercê de qualquer engenhoca tecnicamente possível, por mais mortífera que seja. (ARENDT, 2008, p.11)

As confusões público-privado, câmeras e os excessos de invasões sobre a vida das pessoas, ao mesmo tempo que tais invasões em nada auxiliam no cessar da violência (já que o são por si) e nada provam, quando exigidas pela justiça penal. Esta violência (invasão) produz uma violência virtual que, sob pressão, desencadeia violência física.

As FEBEM's e a falsa educação do ECA (Estatuto da Criança e do Adolescente) na prática. As prerrogativas do ECA na prática mostram-se ora defasadas, ora falsas, sem suso real, mas uma virtualidade para mostrar-se à mídia. As falas dos meninos da FEBEM o comprovam: "eu quero ficar com os grandões no presídio, depois dos 18, quando zera minha ficha policial” (sic). A necessidade se faz premente de educação, uma educação abrangente que inclua ética, moral. Nietzsche já nos ensinava: "nunca se precisou tanto de educadores morais" (sic).

Leis iguais para todos. De que leis, de fato, se fala aqui? Como fica, por exemplo, o Complexo do Alemão, lei igual? Que leis podem ser aplicadas num ambiente pleno de violência e onde qualquer ação torna-se também uma violência?

Importante lembrar do caso Eichmann, debatido por Hannah Arendt, e a forma "judaica" de conduzi-lo, assim como do conceito de autonomia, ou em outros termos, a Bildung, a partir da Paidéia grega e de Rousseau e Hobbes.

Michel Foucault, em seus seminários sobre o Governo de Si e dos Outros e sobre a Hermenêutica do Sujeito aborda e discorre sobre o cuidado de si, como uma questão ampla de uma busca de saúde que vai de encontro com o conhecimento de si, com o saber de seu corpo, com o saber de suas necessidades, de seus desejos, com vistas a uma ampla busca de felicidade, não mais como uma busca utópica, 
subjetiva, inalcançável (talvez como ideal demais!) mas, através desse conhecimento de si, uma felicidade possível, palpável, vivenciável: "A filosofia está assimilada ao cuidado com a alma (o termo é precisamente médico: hugiainein), e esse cuidado é uma tarefa que deve ser seguida ao longo de toda a vida”. (FOUCAULT, 1997, p.120).

A hermenêutica de si - epimeléia heautou (grego) e cura sui (latim) - como princípio de ocupar-se de si, cuidar de si mesmo, obscurecido pelo brilho do Gnôthi seauton. (FOUCAULT, 1997, p.119).

Que fazer de nossas vidas, quem somos, para onde vamos, tudo depende de nós: “o destino do homem está em suas próprias mãos” (SARTRE, 1970, p.09).

Já o dizia Arnaldo Antunes, em O Pulso:

"o pulso ainda pulsa

Peste bubônica, câncer, pneumonia,

Raiva, rubéola, tuberculose, anemia,

Rancor, osteoporose, caxumba, difteria,

Encefalite, laringite, gripe, leucemia

O pulso ainda pulsa

[...]

Hipocondria $[. .$.$] hipocrisia [. .$.$] miopia [. .$.$] culpa [. .$.$] lepra [. .$. afasia".

O que é normal?

Existe uma normalidade?

E se buscarmos a normalidade, como traduzí-la?

\section{Referências}

ARENDT, Hannah. A condição humana. Rio de Janeiro: Forense Universitária, 2008.

BACHELARD, Gaston. A terra e os devaneios da vontade: ensaio sobre a imaginação das forças. São Paulo: Martins Fontes, 2001.

BENJAMIN, Walter. Origem do Drama Trágico Alemão. Belo Horizonte: Autêntica, 2013.

BENJAMIN, Walter. Estética Y Política. Buenos Aires: Las Cuarenta, 2009.

DERRIDA, Jacques. Estados-da-alma da psicanálise. São Paulo: Escuta, 2001.

DERRIDA, Jacques. Da hospitalidade. São Paulo: Escuta, 2003. 
DERRIDA, Jacques. Margens da Filosofia. Campinas: Papirus, 1991.

DERRIDA, Jacques. Paixões. Campinas: Papirus, 1995.

FOUCAULT, Michel. O governo de si e dos outros. São Paulo: Martins Fontes, 2010.

FOUCAULT, Michel. Resumo dos cursos do Collège de France. Rio de Janeiro: Zahar, 1997.

FREUD, Sigmund. Edição stantart brasileira das obras psicológicas completas. Rio de Janeiro: Imago, 1976.

GUATTARI, Félix. As três ecologias. 21 ed. Campinas: Papirus, 2012.

KIERKEGAARD, Sören. Estética y ética em la formación de la personalidad. Buenos Aires: Editorial Nova, 1966.

LACAN, Jacques. Da Psicose Paranóica em suas relações com a Personalidade. Rio de Janeiro: Forense-Universitária, 1987.

LACAN, Jacques. Escritos 1. Buenos Aires: Siglo Veintiuno, 1990.

LACAN, Jacques. Escritos 2. Buenos Aires: Siglo Veintiuno, 1988.

LACAN, Jacques. O mito individual do neurótico. Lisboa: Assírio e Alvim, 1980.

LACAN, Jacques. O seminário 6: o desejo e sua interpretação. Porto Alegre: APPOA, 2002.

LACAN, Jacques. O seminário 7: a ética da psicanálise. Rio de Janeiro: Jorge Zahar Editor, 1998.

LACAN, Jacques. Écrits. Seuil, 1966.

SARTRE, Jean-Paul. $O$ ser $e$ o nada: ensaio de ontologia fenomenológica. Petrópolis: Vozes, 2011.

SARTRE, Jean-Paul. $O$ existencialismo é um humanismo. In: www.odialetico.hpg.ig.com.br/filosofia/livros/ exhuman.htm. Consulta em: 20 de agosto de 2006. Fonte: L’Existentialisme est un Humanisme, Les Éditions Nagel, Paris, 1970.

Recebido em: 19/11/2020.

Aprovado em: 11/12/2020.

Publicado em: 26/12/2020. 